\title{
INTRODUÇÃO GERAL: LIBERDADE COMO POSSIBILIDADE DO HUMANO
}

\author{
Maria Constança Peres Pissarra'
}

\begin{abstract}
Resumo: Na concepção rousseauniana, a liberdade do homem foi construída espontaneamente, por meio da transposição dos obstáculos que lhe obrigou a sair do estado natural, para sua própria manutenção. Portador da perfectibilidade, usou-a para atingir seus objetivos, no entanto, teve que abandonar sua liberdade natural e construir a civil para ter direitos sobre sua própria preservação.
\end{abstract}

Palavras-chave: Rousseau. Liberdade. Perfectibilidade. Independência. Sociedade.

A formação da ideia de liberdade no pensamento ocidental, se confunde com a própria História da Filosofia quando da emergência da polis grega. Nesta, o cidadão é antes de tudo um homem livre, o único que pode exercer o livre pensar e se ocupar dos assuntos da cidade, pois como cidadão participa da vida pública. Ao contrário do escravo, privado de sua liberdade e submetido a um senhor, só o cidadão livre pode deliberar e escolher exatamente por não estar submetido a outrem, isto é, é dotado de livre-arbítrio, do poder absoluto de determinar sua vontade e escolher entre diferentes alternativas sobre diversos assuntos.

Essa oposição expressa a etimologia grega da palavra liberdade - eleutheria - cujo significado era liberdade de movimento do corpo por ausência de qualquer restrição, poder de se movimentar sem qualquer impedimento delimitador. Liberdade era a qualidade de um corpo, mas também a condição política daquele que por natureza não obedecia - o homem livre por oposição ao escravo, por natureza servus. Também a origem latina da palavra - libertas - significa independência por oposição a submissão.

A liberdade continua a ser o maior dos bens, sem ela a condição humana da existência se torna inviável, pois como afirma Rousseau (1973, p. 33), "renunciar a sua liberdade é renunciar a sua condição de homem". 0 que equivale a dizer que, ao contrário dos animais, a força da ação humana é transformadora perante as múltiplas possibilidades de ação e de escolhas que o viver apresenta. Os homens transformam o mundo, os animais não. Para além da rea- 
lidade na qual estão inseridos, inventam outra, guiados pela força de sua vontade e de suas ações. E indagar até onde é possivel ir, até onde se estende nossa vontade, é indagar sobre a possibilidade da liberdade.

Mas, não é fácil definir qual o poder da vontade, ou seja, como é possível estabelecer o limite da liberdade e o que depende da decisão humana ou não para que ela se torne mais do que uma aspiração a ser perseguida e nunca alcançada.

Dessa forma, a definição mais geral de liberdade é a afirmação do senso comum da ausência de qualquer impedimento como condição para a ação livre, isto é, quando se pode fazer aquilo que se quer não importa quando nem como, quando se pode agir sem qualquer pressão limitadora da vontade. Natural ou cultural, a coerção só é possível na relação entre os homens na vida em sociedade. Essa é a primeira dificuldade a enfrentar na compreensão da liberdade, ou seja, a possibilidade de diferentes liberdades coexistirem, o que significa uma liberdade positiva como a possibilidade ou não de controle sobre a liberdade individual como escolha e consequente tomada de decisão.

De um lado, livre-arbitrio, de outro, a impotência humana diante dos desejos, das necessidades, dos impedimentos com que se deparam nossas ações. Como seria possível, então, a liberdade? 0 homem tem ou não uma faculdade de livre-arbitrio? É capaz de se determinar apenas por meio de sua vontade?

A cada novo obstáculo, o objetivo inicialmente estabelecido, distancia-se mais: ao mesmo tempo que persegue seus objetivos, o individuo percebe os obstáculos, naturais ou não, que o impedem de os alcançar, em um amplo exercício de compreensão do que é a liberdade, ou seja, a possibilidade de fazer o que se quiser sem que se seja impedido, sem que se perca a liberdade ou se tenha que renunciar a ela. Isso equivale a dizedr que a construção da liberdade só é possivel na relação de sociabilidade que os homens estabeleceram entre si no processo histórico.

Mas, como toda tensão, esse não é um processo harmônico, como lembra Jean-Jacques Rousseau nas páginas iniciais Do contrato social:

\footnotetext{
[...] o homem nasceu livre e em toda parte se encontra sob grilhões. Portanto, é preciso entender como é possivel proteger essa liberdade natural para que ela não se torne submissão quando da vida em sociedade, é preciso encontrar uma forma de associação que defenda e proteja toda a força comum, a pessoa e os bens de cada associado e pela qual cada um, se unindo a todos, entretanto só obedeceria a si mesmo e permaneceria também tão livre quanto antes (ROUSSEAU, 1973, p. 28).
}

Há uma liberdade natural inalienável e nenhum homem tem direito de se "'despojar' dela, nem qualquer um de subjugar o outro", pois "todo homem tendo nascido livre e senhor de si mesmo, ninguém pode sob qualquer pretexto que seja, subjuga-lo sem seu consentimento" (ROUSSEAU, 1973, p. 32-33). 
Ora, mas essa afirmação não equivale a definição de liberdade como independência ou total ausência de qualquer coerção. É impossivel essa recusa absoluta. Não se é livre porque se recusa os limites que se nos apresentam, quando se recusa o mundo, e sim quando se tenta transformá-lo.

Quando é preciso fazer o contrário do que desejo, não faço, aconteça o que acontecer; da mesma forma, não faço minha própria vontade porque sou fraco. Abstenho-me de agir: pois toda a minha fraqueza se revela diante da ação, toda a minha força é negativa e todos os meus pecados são de omissão, raramente de comissão. Nunca acreditei que a liberdade do homem consistisse em fazer o que quer, mas sim em nunca fazer o que não quer, é esta liberdade que sempre reclamei, que muitas vezes conservei e pela qual provoquei maior escândalo entre meus contemporâneos (ROUSSEAU, 1995, p. 88).

A compreensão da liberdade como a capacidade de não fazer aquilo que não se quer, equivale a pensá-la pela independência em relação ao outro. Como na expressão de Paul Ricoeur (2017, p. 32), "a liberdade de fazer não importa o que não é liberdade. Não basta querer ou não querer, é fundamental fazer, ou melhor, realizá-la. Isso significa indagar pela possibilidade da coexistência das liberdades.

Muito embora, como dito no início deste texto, as concepções filosóficas de liberdade remontem à Antiguidade, é na época moderna que essa discussão se encontra mais alicerçada com a afirmação da razão como única guia segura e libertadora do homem de toda forma de arbítrio. É ao homem que cabe realizar a potencialidade inscrita em sua natureza, como um ato de vontade na direção do "esclarecimento". Como afirma Kant (2008, p. 11),
[...] esclarecimento [Aufklärung] é a saída do homem de sua menoridade da qual ele próprio é culpado. A menoridade é a incapacidade de fazer uso de seu entendimento sem a direção de outro indivíduo. 0 homem é o próprio culpado dessa menoridade se a causa dela não se encontra na falta de entendimento, mas na falta de decisão e de coragem de servir-se de si mesmo sem a direção de outrem. Sapere aude! Tem a coragem de fazer uso de teu próprio entendimento, tal é o lema do esclarecimento.

Na época moderna a noção de liberdade individual se tornou o valor por excelência da vida coletiva, ou seja, a um só tempo a liberdade passou a ser afirmada como um bem individual e universal, o que implica uma única política legítima: a que se dedica aos direitos do indivíduo. Assim, a problemática moral, social e política da modernidade tem como ponto central o direito individual à liberdade. Esse sujeito do lluminismo que ali emerge pode decidir como agir e o que quer alcançar com sua ação, uma vez que pela vontade pode escolher entre diferentes alternativas, e ao escolher, exerce sua liberdade. 
A modernidade nos ensinou que a liberdade é sinônima da autonomia individual. Para o sujeito moderno, só somos livres se governamos a nós mesmos, se estamos sob nossa jurisdição. Só aquele que não está alienado e submisso, ou seja, não é dirigido por outro, pode se autogovernar porque está emancipado.

A reflexão de Rousseau (1995, p. 32) sobre essa questão é esclarecedora ao afirmar que "o principio de toda ação está na vontade de um ser livre". Mais do que uma vontade livre de coerções, é necessário um agente livre. Liberdade e independência são sinônimas porque o agente é livre e não apenas a vontade. Além da liberdade da vontade, é necessária a liberdade de agir.

A solução apresentada pelo pensador genebrino está na formulação do verdadeiro contrato social: a liberdade é obediência à lei que cada um se deu, ela é autonomia. Seu ponto de partida é a noção de estado de natureza, um estado no qual os homens viviam, isolados uns dos outros. Mas, não se trata de perseguir a existência histórica do estado de natureza para ali identificar o momento originário, mas dele partir como paradigma.

Logo nas primeiras páginas do Discurso sobre a origem da desigualdade, Rousseau (1973, p. 233) afirma que "o mais útil e o menos avançado de todos os conhecimentos humanos, parece ser o do homem". E para alcançar tal objetivo, se faz necessário "afastar todos os fatos" e voltar a esse estado pela reflexão, como uma volta do homem sobre si mesmo, sobre o que há de mais natural nele - sua própria natureza - antes que a sociedade o tenha desfigurado. Assim, há na argumentação rousseauniana, uma função normativa do estado de natureza: não é possivel compreender o que é o homem historicamente, ou seja, o homem contemporâneo da sociedade civil, sem recorrer ao estado de natureza como critério para avaliar a distância que separa este da sua origem.

\footnotetext{
Naquele estado, os homens viviam isolados, não estavam submetidos a laços de dependência, nem de interesse uns com os outros. Em uma palavra, a desigualdade não estava presente ali uma vez que é o resultado do desenvolvimento das necessidades e da interdependência dos indivíduos e não poderia existir em um estado de isolamento e de ignorância sobre tudo que não fosse a simples manifestação do instinto de conservação. 0 homem da natureza era livre, igual e naturalmente bom (ROUSSEAU, 1973, p. 234-235).
}

E como a história caminha sempre em direção ao futuro e não ao passado, os laços de sociabilidade gradativamente se formaram até o surgimento de fato das sociedades e à instituição dos pactos fundantes: à saída do estado de natureza corresponde a entrada no processo histórico. Como consequência, o homem desnaturado perdeu esse direito natural. Portanto, trata-se de indagar como seria possivel o advento da história sem a perda da liberdade. A passagem do estado de natureza regulado pela lei natural - para o estado de sociedade - regulado pela lei civil, ou seja, do direito natural para o direito civil e da liberdade 
natural para liberdade civil, "produz no homem uma mudança significativa, substituindo na sua conduta a justiça ao instinto e dando às suas ações a moralidade que antes Ihes faltava" (ROUSSEAU, 1973, p. 42). A civilização "negativa" posto que desnaturada, não se resolve por uma volta ao estado de natureza hipotético, mas pela refundação moral e política da civilização. Não é possivel uma solução de continuidade.

De acordo com Rousseau, só pela liberdade civil o homem pode alcançar sua verdadeira humanidade, pois pelo verdadeiro contrato social o homem perde "sua liberdade natural e um direito ilimitado a tudo aquilo que o tenta e que pode alcançar; o que ele ganha é a liberdade civil e a propriedade de tudo aquilo que possui" (ROUSSEAU, 1973, p. 42). E, completa, a essa aquisição soma-se outra: "a liberdade moral, a única que torna o homem verdadeiramente senhor dele, pois apenas o impulso do apetite é escravidão e a obediência a lei que se prescreve a si mesmo, é liberdade" (ROUSSEAU, 1973, p. 37).

Esse estado de natureza ficcional tem tripla função no pensamento de Rousseau: primeiro, assegurar ao homem civilizado a fé na sua bondade e inocência primeiras, segundo, evidenciar a liberdade como a causa da paixão; terceiro, fazer do primitivo um modelo a ser restaurado, mas em bases éticas e cívicas e não mais naturais. Como ensina o vigário de Saboia ao seu pupilo, a liberdade, como a justiça e a bondade, não deve ser apenas uma abstração, mas algo que deve vir de dentro da alma.

$E$, nas sociedades concretas, é essa a função do verdadeiro contrato social: conciliar o interesse de cada um com o interesse de todos, equilibrar o utilitarismo sempre subjacente com as demandas da liberdade do ponto de vista político, mas também ético. Se a liberdade civil é para cada um dos membros da sociedade unida pelo contrato, um ganho, pois protege sua vida, sua liberdade e seus bens, de tal forma que todos ao porem sua pessoa em comum, permanecem tão iguais quanto antes, seu valor maior valor está no exercício de sua a liberdade cívica na participação dos assuntos de poder no exercício da vida política. A ação contraria é a alienação, é a perda do gosto pela liberdade. Daí a afirmação, aparentemente contraditória, sobre a desobediência à vontade geral estabelecida pelo pacto social: quem quer que assim aja, deve ser obrigado pelo próprio corpo social "a ser livre".

Esse corpo social é não só um corpo político, mas também um corpo moral, resultante do pacto estabelecido por todos e que enquanto corpo moral, só tem realidade se for aquilo para o qual foi estabelecido. A liberdade fora do limite da lei, é a sua morte, não é nada. É preciso aderir obstinadamente a lei que se deu, o que impede qualquer manifestação das liberdades individuais. Aquela deve servir de parâmetro único a estas, balizada pela vontade geral, a única referência possivel das vontades particulares.

A sociedade contemporânea mais do que nunca continua a afirmar a crença no progresso sem limites e linear da humanidade. Trata-se de acreditar que a utilização cada vez mais ampla e incondicional do conhecimento científico e de suas tecnologias, dará aos homens uma liberdade mais e mais ilimitada. Ecoa, ainda hoje, o "espírito das Luzes" do século de 
Rousseau, para o qual o conhecimento liberta o homem de toda ignorância e ao torná-lo autônomo, também o torna livre.

Mas, como foi visto acima, o pensador genebrino já revelou em sua analise a contradição dessa crença: o que torna melhor o homem não é o progresso, mas a sua capacidade de se aprimorar e ao que o rodeia - a perfectibilidade. Como afirmou no Discurso sobre as ciências e as artes, o progresso moral nem sempre acompanhou o progresso científico. Acreditando-se livre, a humanidade mais escravizou do que emancipou a si mesma.

Assim, ainda hoje, cabe a pergunta: somos mais livres? Parece que não, pois as técnicas de poder que estão presentes nas sociedades contemporâneas tendem a influenciar a vida psíquica negativamente ao convertê-la na sua principal força de produção.

Essa nova técnica de dominação ou psicopolítica, se traduz em uma nova prática muito mais sedutora na eficácia da submissão. Sua grande estratégia é fazer o sujeito que a ela se submete se acreditar livre. Mas, afirma o pensador germano-coreano, a grande perversidade do psicopoder é que apoiado em uma ferramenta como o Big Data, utiliza todos os dados dos indivíduos ao acessarem suas redes sociais. Aquilo que afirmamos como a mais irrestrita liberdade do acesso incondicionado ao que quer que seja, acaba por se tornar uma armadilha e perda da liberdade, a revelar antes uma profunda crise e não a sua possibilidade ilimitada:

A liberdade foi um episódio. "Episódio" significa "entreato", intervalo entre dois atos. 0 sentimento de liberdade situa-se na transição de uma forma de vida para outra, até acabar por se revelar como uma forma de coação. À libertação segue-se, desse modo, uma nova submissão. É esse o destino do sujeito, que literalmente significa, "estar submetido".

\title{
General introduction: freedom as a human's possibility
}

\begin{abstract}
In the Rousseaunian conception, man's freedom was built spontaneously, through the transposition of obstacles that forced him to leave the natural state, for his own maintenance and salvation. A bearer of perfectibility, he used it to achieve his goals, however, and still uses it because he became a slave to it. Came out of it had to abandon its natural freedom and manufactured to build civil freedom to have rights over for its own preservation.
\end{abstract}

Keywords: Rousseau. Freedom. Perfectibility. Independence. Society

\section{REFERÊNCIAS}

EIGELDINGER, F.; TROUSSON, R. Dictionnaire de Jean-Jacques Rousseau. Paris: Honoré Champion, 1996. 
JAFFRO, L. Comment produire le sentiment de l'existence? Jean-Jacques Rousseau et l'exigence d'authenticité. Paris: Garnier, 2014.

KANT, I. Resposta à pergunta: 0 que é o Esclarecimento? Tradução de Luiz Paulo Rouanet. Brasilia: Casa das Musas, 2008.

RICOEUR, P. 0 mal e a liberdade. Revista Opinião filosófica, v. 08, n. 1, 2017.

ROUSSEAU, J.-J. OEuvres complètes. Organisation Bernard Gagnebin et Marcel Raymond. Paris: Gallimard, 1959-1995. 5 t. (Bibliothèque de la Pléiade). ROUSSEAU, J.-J. Do contrato social. Tradução de Lourdes Santos Machado. São Paulo: Abril Cultural, 1973.

ROUSSEAU, J.-J.. Emílio ou Da Educação. Tradução Roberto Leal Ferreira. São Paulo: Martins Fontes, 1995.

ROUSSEAU, J.-J. Discurso sobre a origem e os fundamentos da desigualdade entre os homens. Tradução de Lourdes Santos Machado. São Paulo: Abril Cultural, 1973.

ROUSSEAU, J.-J. Discurso sobre as ciências e as artes. Tradução de Lourdes Santos Machado. São Paulo: Abril Cultural, 1973.

STAROBINSKI, J. La transparence et l'obstacle. Paris: Gallimard, 1976. (Bibliothèque de la Pléiade).

Recebido em julho de 2018. Aprovado em outubro de 2018. 